\title{
Valores entre los infantes
}

\author{
Goretti Briseño Díaz ${ }^{1}$ \\ Rosa María Contreras Martínez ${ }^{2}$ \\ Montserrat Hoyo Landaverde ${ }^{3}$ \\ Daniela Mendoza $^{4}$
}

\section{Introducción}

La educación centrada en valores ha obtenido mayor importancia a partir de los 90`s gracias al movimiento de reformas educativas realizadas por diversos países en Europa, Asia, Latinoamérica y África (Benavot, 2002: 61-62), ésta ha recibido apoyo de organismos internacionales como la Organización de las Naciones Unidas (O.N.U.), la Organización de las Naciones Unidas para la Educación, la Ciencia y la Cultura (U.N.E.S.C.O.) Organización de Estados Iberoamericanos (O.E.I.) entre muchas más, estas dependencias han llevado a cabo foros en los cuales la problemática de la convivencia armónica entre los individuos en sociedad arroja resultados desalentadores ya que cada día se va perdiendo significado de valor en el tema de la moral . (U.N.E.S.C.O: 2002:2).

Una de las medidas para contribuir a una sociedad más tolerante, ha sido apegarse a un programa que fomente, fortalezca y propicie una educación sustentada en valores universales, propios de cada entorno nacional, sostenidos por la ciencia y cultura., para poder realizar lo anterior los sistemas educativos nacionales han realizado reformas curriculares en planes y programas incorporando una materia que enseñe valores.

\section{Problema de Investigación}

"Es algo particularmente urgente en una era de globalización, en la que puede haber el

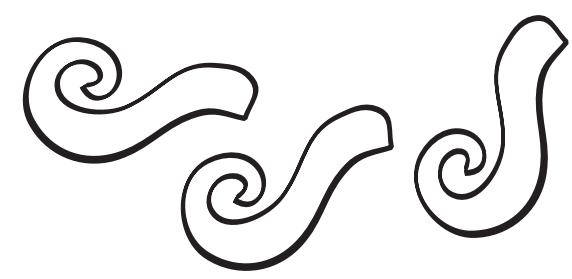

peligro de que los valores humanos fundamentales queden sacrificados en nombre del progreso de que se pierdan a causa de ideologías seculares y destructivas" Benedicto XVI.

Cada vez se percibe más $<<$ una profunda crisis de valores detrás de la crisis material que sufrimos $>>$ donde se da más importancia $<<$ al parecer que al ser, al tener que al hacer $>>$ y, donde cuentan más $<<$ las ambiciones individuales, libres de todo compromiso con la sociedad actual $>>$ (Juan Vicente Herrera. Premios Castilla y León).

Por ello el problema de esta investigación plantea, identificar los principales valores éticos que niños y niñas reciben a partir de la educación en su hogar en el contexto de Molango.

\section{Objetivos}

1. Identificar si los niños de la comunidad de Molango conocen el significado y la importancia de los valores en su vida, para conocer el tipo de actitudes y acciones que tendrán al crecer y convertirse en actores clave en la sociedad.

2. Reconocer la jerarquización axiológica de los valores que los pequeños puedan poner en práctica.

3. Identificar si los sujetos respetan las diferentes formas de valores presentadas en su vida.

1 Octavo semestre de la Licenciatura en Psicología. (yaco_00@hotmail.com)

2 Octavo semestre de la Licenciatura en Psicología. (m_rosmari@hotmail.com)

3 Octavo semestre de la Licenciatura en Psicología. (monx_90land@hotmail.com

4 Octavo semestre de la Licenciatura en Psicología. (dany_7kiss@hotmail.com) 


\section{Preguntas de Investigación}

1. ¿Cuál es el significado de "valor" para los niños?

2. ¿Cuáles son los principales valores humanos que más ponen en práctica?

3. ¿Los sujetos conocen los diferentes valores humanos?

\section{Justificación}

Con base en el proyecto P.E.R.L.A. atenderemos la necesidad de democratización del conocimiento cuyos principales objetivos son orientar el proyecto a la innovación y transformación social, conocer las necesidades de los sujetos a partir de una metodología pertinente y participativa, establecer redes de difusión de la información obtenida, propiciar que las comunidades mejoren sus condiciones de vida y sean sujetos de su propio destino, la pérdida de los valores humanos crea desorientación y frustración en la sociedad, una correcta jerarquización no solo ayudará a las personas en su vida diaria sino también dará paso a una transformación positiva de la sociedad.

\section{Recursos}

Esta investigación es viable ya que los recursos son alcanzables ya que utilizaremos recursos humanos (investigadores, población a investigar) recursos económicos (estancia en la comunidad) y recursos materiales (programas e investigación a desarrollar).

El tiempo asignado en la comunidad tendrá un periodo de 5 días.

Habilidades de los investigadores: las investigadoras cuentan con empatía hacia la comunidad de interés y sobre todo cuentan con la determinación necesaria para adaptarse al ambiente propuesto.

Acceso al lugar: es en el estado de Hidalgo.
Marco conceptual

El tema de la investigación dentro de un sistema educativo trata sobre los valores que los padres y los maestros les trasmiten a los niños de acuerdo con el contexto en el que cada uno se va desarrollando y cómo los valores los llevan a la práctica en la vida diaria.

La educación puede definirse como el proceso de socialización de los individuos. Al educarse, una persona asimila y aprende conocimientos. La educación también implica una concienciación cultural y conductual, donde las nuevas generaciones adquieren los modos de ser de generaciones anteriores.

El proceso educativo se materializa en una serie de habilidades y valores que producen cambios intelectuales, emocionales y sociales en el individuo. De acuerdo al grado de concienciación alcanzado, estos valores pueden durar toda la vida o solo un periodo de tiempo. En el caso de los niños, la educación busca fomentar el proceso de estructuración del pensamiento y de las formas de expresión. Ayuda en el proceso madurativo sensoriomotor y estimula la integración y la convivencia grupal.

La etapa de infancia es muy importante en la vida del niño porque es cuando el aprende y crece de diferentes maneras. Cada cosa que sucede en la vida del niño tiene un gran significado.

Este crecimiento es diferente en cada infante, por lo tanto tiene su propio rango de tiempo.

Ahora bien, un valor en sentido axiológico no existe por sí mismo. Los valores podríamos decir son "cualidades o propiedades" de los objetos, pero no solo de objetos físicos, ya que este tipo de cualidades también de adhieren a las formas y estados psicológicos. Es por ello que hablamos de un sentido del "valor" como intrínsecos al ser humano, pues existen desde el momento de su nacimiento. 


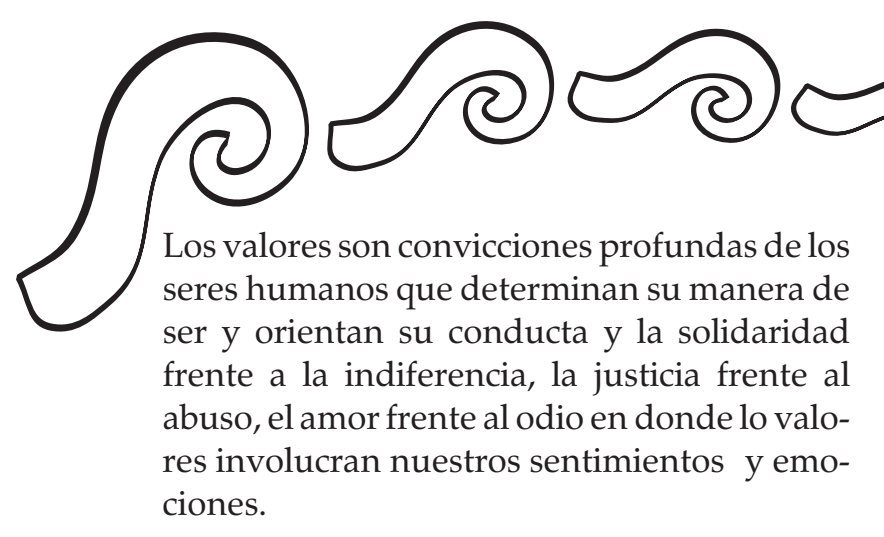

Cuando valoramos la paz, nos molesta y nos hiere la guerra y cuando valoramos el amor y lastima el odio, es necesario saber que los valores, las actitudes y conductas están relacionados.

\section{Marco histórico}

"Valor", en nuestra lengua, proviene del latìn "valor", "tener salud", "estar bien", la forma romana de despedida era "váleas", que estés bien. Luego el término adquirió en sentido de "tener vigor" no sólo físico sino también de ánimo, que éticamente es parte de la virtud de la fortaleza. (Aristóteles, Política 1970, Pág. 1222).

Hoy, sin embargo, cuando se habla de "valores" se entiende más bien como significado a un valor monetario. Al hablar de "valor" estamos tocando el tema central de la axiología. "Antiguamente, los valores como bien, belleza, justicia, fueron el tema central de las tesis de varios filósofos, pero no fueron estudiados como valores en sí, pues el valor para ellos estaba incluido en el ser, $e$ incluso hay quien dice que los valores no son más que los viejos modos del ser". Aristóteles, Política 1970).

Los valores son convicciones profundas de los seres humanos que determinan su manera de ser y orientan su conducta. Involucran nuestros sentimientos y emociones como actitudes y conductas que están relacionados. (Beneke, 1822).

Se jerarquizan por criterios de importancia de la persona, forman parte de su identidad. Orientan sus decisiones frente a sus deseos e impulsos y fortalecen su sentido del deber ser.
Los valores se aprenden desde la temprana infancia y cada persona les asigna un sentido propio, cada persona, de acuerdo a sus experiencias, conocimientos previos y desarrollo cognitivo, construye un sentido propio de los valores. Aunque a todos nos enseñen que la honestidad es algo deseable, y aunque todos lo aceptamos como cierto, la interpretación que haremos de este valor, el sentido que le encontraremos en nuestra vida, será diferente para cada persona.

Los valores y su jerarquización pueden cambiar a lo largo de la vida. Están relacionados con los intereses y necesidades de las personas a lo largo de su desarrollo.

Los valores de los niños pequeños están definidos en buena medida por sus necesidades de subsistencia y por la búsqueda de aprobación de sus padres: sustento biológico, amor filial.

Los adolescentes guían sus valores personales por su necesidad de experimentación y autonomía: amistad, libertad. Mientras que en la edad adulta se plantean nuevas prioridades: salud, éxito profesional, responsabilidad. Algunos valores permanecen a lo largo de la vida de las personas.

\section{Marco referencial}

Santana Lourdes Denis. Venezuela (2010) Explica cuáles y de qué modo son expresados los valores de manera cotidiana dentro del aula de educación básica y superior.

La intención del estudio de dicha autora es construir una interpretación acerca de cómo se manifiesta la dimensión valorativa en una situación real y particular de enseñanza aprendizaje, a partir de la observación del intercambio cotidiano de docentes y alumnos en un aula de educación Básica y un aula de educación superior.

Este es un estudio interpretativo que aborda la 


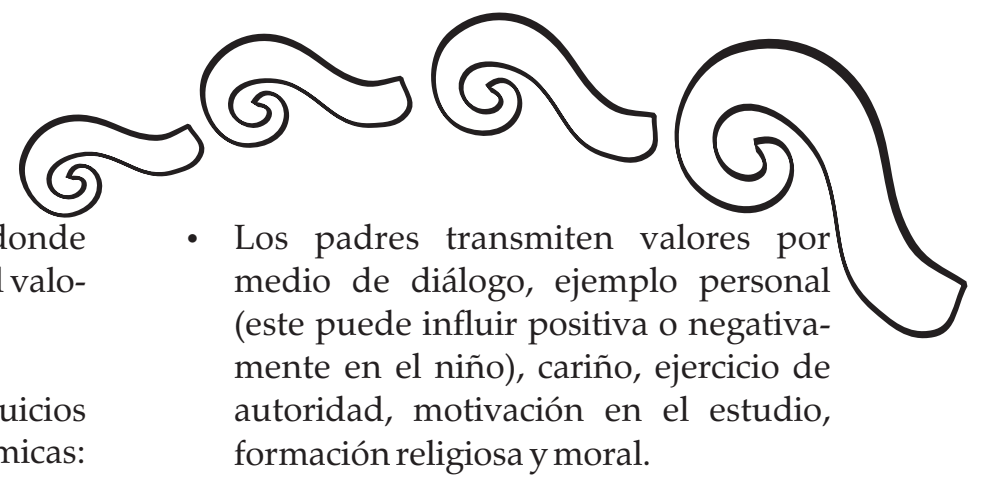

La investigación analiza acciones y juicios individualismo- colectivismos, competenciasolidaridad, libertad-represión, conformismo-resistencia, en el marco de las teorías, de Reproducción- transformación, Curriculum oculto (Según Jackson tiene que ver con el 99\% de lo que ocurre en las aulas y muchas veces se hace de forma inconsciente), violencia simbólica y teoría de la resistencia.

El niño va adquiriendo los valores en la escuela con el paso del tiempo por medio del ejemplo de su guía o maestro, el niño las vive día con día en el salón de clases en cuanto a su interacción espontánea con los demás.

El maestro es un gran ejemplo y tiene un papel importante en los niños ya que posee una gran responsabilidad para la formación de éstos, este debe ser congruente en lo que dice (lo que enseña en un salón de clases) y lo que hace (como los conocimiento y valores los pone en práctica en su vida cotidiana). Los valores no pueden quedarse en el mundo de las ideas ya que toman vida o tienen valor cuando se reflejan en las acciones y así puedan tener un significado para el niño. (Hortensia López Lorca, 2006).

La siguiente investigación cualitativa se basó en entrevistas que fueron aplicadas a alumnos y padres de familia para conocer cómo los niños perciben los valores y cómo éstos son transmitidos y asimilados por los mismos.

Familia y responsabilidad: un estudio cualitativo

La familia como primer núcleo social. La familia juega un papel preponderante en la transmisión de valores.

Los resultados obtenidos de las entrevistas se llego a estas conclusiones:

- Muchos de los padres de familia no establecen condiciones apropiadas para con sus hijos ya no carezcan de tiempo con ellos. Debido a la indiferencia de los progenitores hacia sus hijos, la autoridad se diluye.

- La investigación hace mención de algunas propuestas para mejorar la tarea formativa en los padres de familia y profesores.

- Educación para el matrimonio: asesorar en la responsabilidad que tienen los padres hacia los hijos.

- Formación de los profesionales de la educación: que los docentes cuenten con capacitación para que puedan coadyuvar con los padres de familia en la formación de los hijos.

En conclusión, el primer factor social fundamental y natural para un niño es la familia, la escuela se presenta como un segundo hogar y como una herramienta de socialización provechosa donde el niño va adquiriendo una formación integral, habilidades cognitivas, productivas y lo más importante: en las aulas puede vivir en compañía las dinámicas socioculturales enfocadas a los valores.

\section{Marco teórico}

A finales del siglo XIX y principios del XX, los valores se convierten en un importante tema filosófico. En Viena surge la denominada teoría subjetivista según la cual los valores se dan debido a la estimación por parte del sujeto, es decir, el sujeto es el que le da valor a las cosas. Esta teoría es iniciada por Meinong y por 


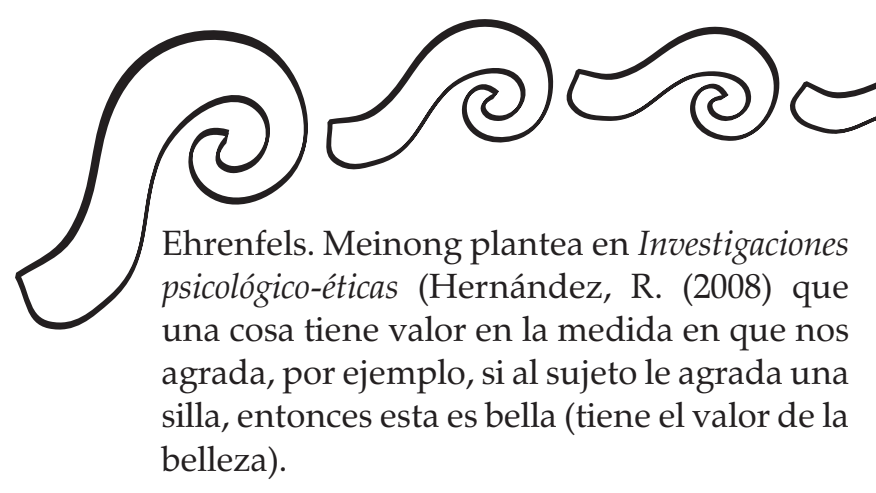

Ehrenfels critica esta postura, ya que según esta teoría solo tienen valor las cosas existentes, o bien únicamente las que podemos percibir tienen una existencia concreta y son agradables. Pero también valoramos y deseamos las que no existen tales como el bien moral jamás realizado o la justicia perfecta. Según Ehrenfels en La Teoría de los Valores (Hernández, R. 2008) hay que buscar los valores no en el agrado sino en el deseo y en la medida en que el hombre desea algo, esto tiene valor. En esta visión, si el hombre desea, como mencionaba, la justicia perfecta o el bien moral jamás realizado, estos adquieren valor.

La teoría subjetivista tiene su pilar en: la apreciación por parte del sujeto, este es quien le da el valor a las cosas, por agrado o por deseo, de ahí que con facilidad se pueda caer en un relativismo de los valores.

Para contrarrestar el relativismo de la escuela subjetivista, Max Scheler en La Ética Material de los Valores (Hernández, R. (2008) propone una teoría en la que los valores deben ser considerados por lo que son y no por el agrado o el deseo del sujeto, con lo cual brinda objetividad a los valores y los instaura como el fundamento de su ética. Con esta postura tiene la necesidad de poner pie firme a la moral y estabilizarla.

\section{Características de los valores}

Los valores deben de tener un depositario es decir, se deben de manifestar en algún objeto, pero es importante señalar que a pesar de esta relación entre el valor y el depositario u objeto, los dos tienen una existencia independiente, por ejemplo, enfoquémonos en el mural de Diego Rivera del Teatro de los Insurgentes, llamado La historia del teatro, y podemos decir que dicha obra es bella. Aquí hablamos del valor de la belleza que para manifestarse debe de estar contenido en algún depositario, en este caso la obra del muralista mexicano, o para decirlo con otras palabras, podemos hablar de la belleza del mural gracias a que existe y lo podemos ver y apreciar.

Según Scheler en Ética Material de los Valores (Hernández, R. (2008), los valores son a priori, independientes de toda experiencia. Sabemos que los valores son autónomos con respecto a sus depositarios u objetos que están en el mundo y de los cuales tenemos una experiencia particular (obras de arte, monumentos, actos humanos, etc.). Esta independencia hace que los valores sean eternos e inmutables y que trasciendan a la experiencia. Tenemos el caso de un vendedor que deja de lado la honradez que le caracterizaba y realiza un fraude a su cliente debido a que puede obtener una gran ganancia. No por eso el valor -en este caso la honradez- deja de existir, ya que siempre se manifestará en otras personas. Si una pintura que es bella se rompe, no deja de existir el valor de la belleza. El cambio que un depositario $\mathrm{u}$ objeto tenga no afecta en nada al valor. La belleza siempre ha existido, lo mismo que la justicia o el amor y no cambian, lo que puede variar es el depositario, pero el valor en sí, no se altera.

Los valores se captan de manera emocional. Aquí los ojos de la razón son ciegos y dejan a la emotividad la captación de valores. Scheler pone en marcha "el orden del corazón" del que hablaba Pascal en "Pensées". Esto lo podemos ejemplificar con una obra de arte: cuando la ves o la escuchas, si es bella, te produce cierto estremecimiento y pone a flor de piel tus sentimientos. En una melodía, no te preguntas cuántas notas ni qué ritmo tiene, porque estarías cayendo en un racionalismo que no te permitiría el goce de la belleza de la obra. Simplemente te dejas llevar por la sensación que te produce la melodía y esta se da por medio de la captación emotiva: te produce una emoción 


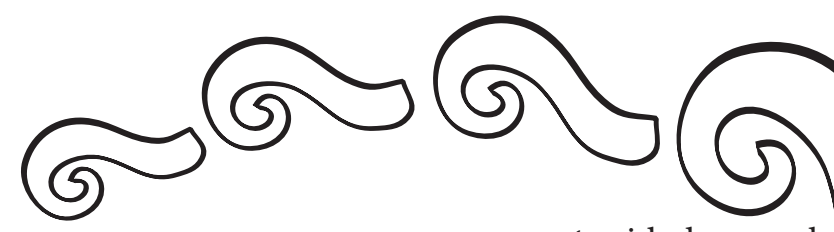

incontenible que está lejana a la razón y que tiene su orden propio: el orden del corazón.

En la Teoría subjetivista de Meinong en la cual hace mención que el sujeto es el que le da valor a las cosas la polaridad, por un valor positivo siempre habrá un valor negativo o disvalor con existencia propia. Encontramos contraria a la belleza, la fealdad, a la justicia, la injusticia, a la lealtad, la traición, etcétera.

Scheler Hernández, R. 2008 en la Ética Material de los Valores, propone: que los valores deben de ser jerarquizables. Para hacer una jerarquización de valores se debe tomar en cuenta:

- Relación a priori

- Que se apliquen a todas las personas, por y para siempre

- Que partan de los valores más elementales a los más complejos

1) Base: Valores de lo agradable y lo desagradable a. Estados afectivos de placer o dolor

2) Segundo Lugar: Valores Vitales a. Tienen que ver con el bienestar: salud, enfermedad, muerte, vejez, juventud, etcétera.

3) Tercer Lugar: Valores Espirituales: puro conocimiento de la verdad, en esta posición se encuentra la filosofía.

4) Cúspide: Valores de lo Santo y Profano, ya que estos valores están relacionados con lo religioso y espiritual ya que estos pueden tener gran proximidad o alejamiento a lo santo.

\section{Metodología}

\section{Enfoque Cualitativo}

La finalidad de esta investigación es comprender la realidad de las personas de la población de Molango, y por medio de esta indagación dar esta vías de mejora ya que una población

con escasos recursos y oportunidades puede ser una comunidad con bajo nivel educativo. Como investigadoras nos introduciremos al ambiente natural para poder obtener experiencias de manera directa y así poder observar, entender y profundizar las conductas buenas y malas de los niños de las primarias de Malango.

Esta investigación es cualitativa ya que posee una serie de características, las cuales iremos comentando a continuación:

- La investigación cualitativa es una ciencia social, holística -Esta investigación es interna (humanista) ya que los datos que se obtienen de esta se enfocan en las culturas, afectos, tradiciones e ideología de las personas de Molango y estos datos son profundos, subjetivos y enriquecedores. Y la actitud del investigador es subjetiva-objetiva ya que nosotras para llegar a la verdad nos vamos a apegar a los datos que el objeto nos dé.

\section{Alcance, Exploratorio}

Debido a que nuestro tema a investigar es Valores entre los Infantes, el alcance que queremos lograr es el fomentar los valores principales entre los niños para que se familiaricen y los lleven a la práctica con sus compañeros de clases como en la casa y a cualquier lugar en donde exista una convivencia que se lleve a la práctica los diferentes valores adquiridos.

Les queremos hacer conciencia del bien que conlleva actuar por medio de valores, el bienestar que uno siente al aplicar actitudes de bien hacia el otro como la otra persona también siente un bien al tratarle con algún valor como es el respeto, la solidaridad, la honestidad y muchos otros que son primordiales en el trato cotidiano.

Como inicio les daremos a los niños ejemplos y les preguntaremos qué harían en diferentes situaciones (relacionadas con algún valor) y 


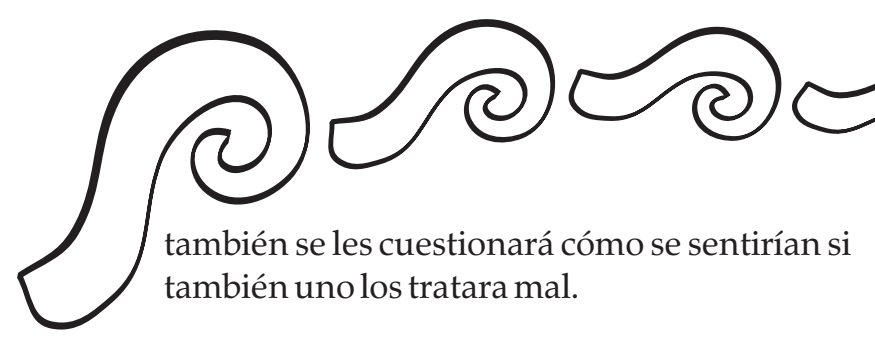

Nos gustaría poder llegar más allá con este tema, no sólo en la institución, sino en la comunidad y con su familia, ya que el ejemplo que más toman en cuenta a esta corta edad, es el que sus padres o familiares cercanos les transmiten.

El propósito de este tema es que se puedan fomentar los valores para un desarrollo moral en la sociedad en la que pertenece cada infante hoy en día los valores los han dejado a un lado, tanto en las convivencias humanas como en los medios de comunicación y es importante que se transmita una buena formación de los valores.

\section{Diseño: Transversal}

Nuestro diseño será no experimental ya que no se manipularán las variables de la investigación, solo se observaran los fenómenos socioeducativos enfocados en la ética. Tomando en cuenta el tiempo en el que recogeremos datos utilizaremos un diseño transversal, donde se recolectará información en un solo momento, en un tiempo único, el propósito será describir variables y su incidencia de interrelación en un momento.

\section{Supuesto}

La investigación se llevará a cabo en una población que tiene como finalidad ayudar a los niños a que puedan conocer los valores ya que se les podrá enseñar con base en su situación educativa en la que están insertos.

Las preguntas se aplicarán en escuelas marginadas y se realizarán de acuerdo a las necesidades que se vayan presentando, ya que el resultado puede variar de acuerdo a las condiciones presentadas durante la investigación.

Para ver cuáles son las necesidades que el infante presenta es necesario trabajar los valo- res de manera práctica y dinámica para un mejor desarrollo dentro y fuera de la comunidad en la que viven.

\section{Población y muestra}

Los sujetos con los que trabajaremos son niños de entre seis y ocho años, que estén cursando primero o segundo grado a nivel primaria, las principales características de los infantes con base en una fuente de consulta confiable nationalnetworkforchildcare son:

- Conocen y se identifican como personas.

- Capaces de tomar responsabilidades y controlar impulsos.

- Proceso notable en coordinación motora.

- Cuentan con poca capacidad de atención.

- Pueden representar mentalmente cosas u hechos.

- Centrados y gobernados por sus sentimientos.

- Distinguen lo propio de lo ajeno.

- Gran imaginación.

El contexto de las poblaciones a visitar es el siguiente:

MOLANGO:"Molango de Escamilla" es una ciudad del Estado de Hidalgo en la sierra madre oriental al noreste de la república Mexicana

Población: Según el Instituto Nacional de Estadística y Geografía mediante el II Conteo de Población y Vivienda 2005, la población total de Molango es de 3,906 habitantes, de los cuales, 1867 hombres y 2039 son mujeres. 


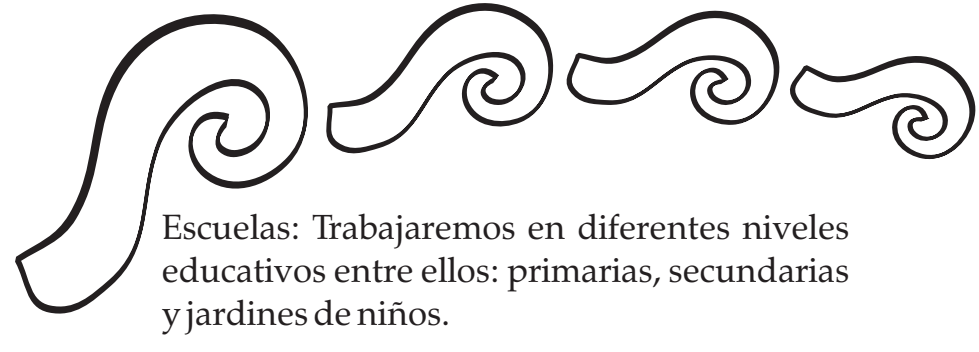

TENANGO: La localidad de Tenango de Doria está situada en el Municipio de Tenango de Doria (en el Estado de Hidalgo). Tiene 2096 habitantes.

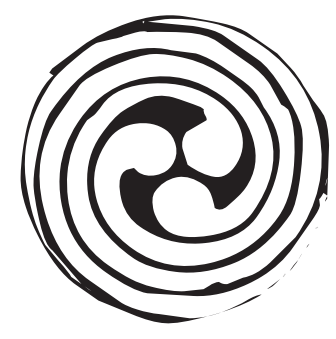

CHALMA: La localidad de Chalma está situada en el Municipio de Lolotla (en el Estado de Hidalgo). Tiene 432 habitantes

IXMOLINTLA: La localidad de Ixmolintla está situada en el Municipio de Molango de Escamilla (en el Estado de Hidalgo). Tiene 253 habitantes

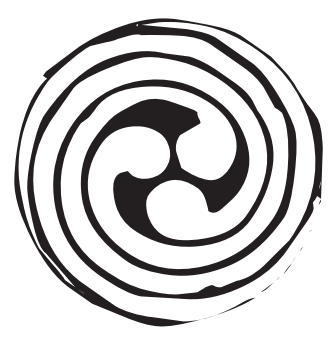

PEMUXTITLA: La localidad de Pemuxtitla está situada en el Municipio de Molango de Escamilla (en el Estado de Hidalgo). Tiene 240 habitantes

La muestra será no probabilística ya que someteremos la investigación a la realidad de los sujetos que se presten para realizar el trabajo, los resultados para seguir con el proyecto vendrán de aquellas personas que se presten a compartir su realidad con los investigadores.
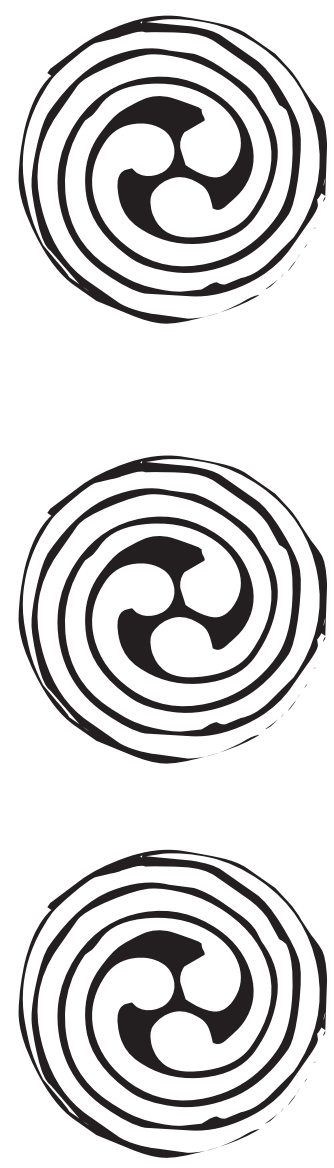


\section{Entrevista. Investigación "Valores entre los infantes"}

Folio:

Comunidad:

Nombre de la escuela:

Edad:

Sexo:

\section{Valor útil: Comunicación no verbal}

1. ¿Cuando tu mamá está haciendo la comida, qué haces tú mientras?
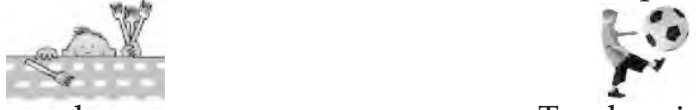

Pones la mesa

Te sales a jugar

Valor Vital:

2. ¿Cuándo sales al recreo te gusta jugar algún deporte o te gusta ver jugar a los demás y no Involucrarte en el juego?

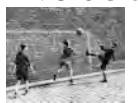

Juego con mi amigos

Los veo jugar

Valor Moral:

3. ¿Qué harías si te encuentras juguete que tiene escrito el nombre del dueño? ¿lo devuelves o telo quedas?

Nolo devuelvo
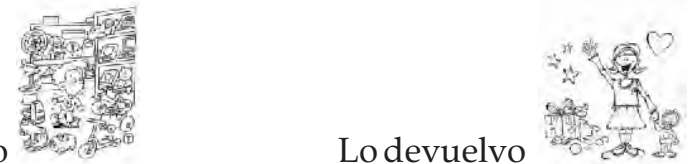

Valor Intelectual:

4. Si tienes dentro de tu comunidad a un amigo que esconde las cosas de los demás. ¿lo acusarías?

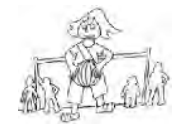

Seguiría jugando con él

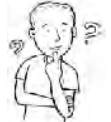

Le diría mis padres

Valor religioso:

5. Es viernes por la noche y tú no puedes dormir ya que un miembro de tu familia te contó una historia de terror, para sentirte más seguro tú:

Prendes la luz

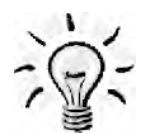

Dices alguna oración

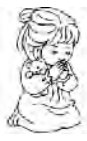

Valor estético:

6. Dos niñas nuevas entran a tu salón de clases, una de ellas es hermosa sin embargo es muy grosera porque nunca presta sus cosas, la otra niña aunque no es muy bonita es muy amable a quien de estas dos niñas le pedirías que fuera tu amiga?

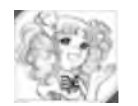

La niña bonita pero grosera

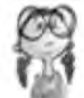

La niña fea pero amable

7. ¿Si tuvieras una oportunidad, como ayudarías a tu comunidad? 


\section{Análisis y Resultados}

A continuación se mostrarán las siguientes gráficas, en las cuales se representan los datos obtenidos en las comunidades de Molango.

\section{Tenango, Escuela Primaria: José Ma. Morelos} y Pavón

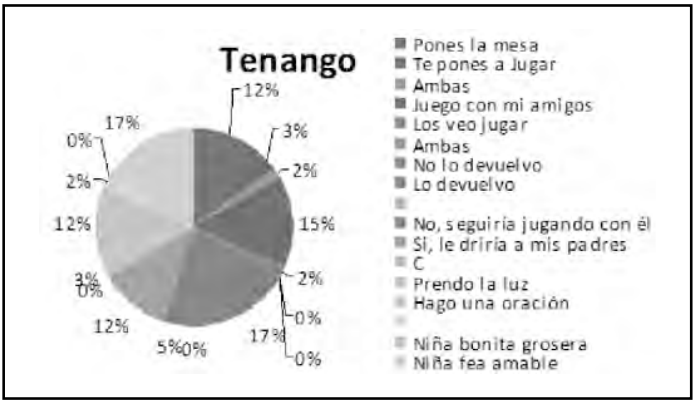

El primer día en Molango tuvimos acceso a la Primaria José Ma. Morelos y Pavón en la cual realizamos una entrevista sobre los valores a 10 alumnos de $1^{\circ}$ y $2^{\circ}$ grado. Nos pudimos percatar que de acuerdo a los resultados obtenidos de la muestra de los alumnos de dicho grado tienen el $12 \%$ de los niños practicaban el valor Útil ya que estos preferian ayudar a poner la mesa en la hora de la comida y un 3\% prefirió jugar en dicho momento. De acuerdo al valor Vital y la actividad física el 15\% de los niños preferian salir a jugar en la hora de su descanso, mientras tanto el $2 \%$ prefería ver jugar a los demás.

Respecto al valor Intelectual, el 12\% decidió que le diría a sus padres y el $3 \%$ dispuso que seguiría jugando con el niño y/o niña.

En cuanto al valor religioso el $12 \%$ de los niños prefirió tener contacto religioso, cuando se sintiera en una situacion de miedo. El último valor utilizado en la entrevista es el estético y todos los niños coincidieron al alegir la esencia de las personas y no su físico. Los pequeños afirmaron que sí tuvieran una oportunidad para ayudar a su comunidad la ayudarían no tirando basura.
Chalma, Escuela Primaria: Netzahualcóyotl

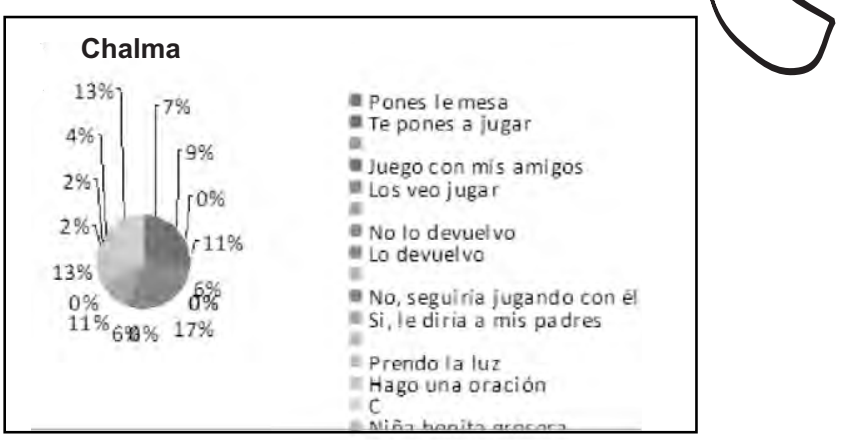

El segundo día visitamos la comunidad de Chalma, nos enfocamos en la Primaria Netzahualcóyotl para impartir las mismas entrevistas, ahora con el apoyo de 9 niños y niñas del mismo grado.

En esta comunidad conocimos que el valor Útil en el hogar obtuvo el $9 \%$ entre los niños que ayudaban a poner la mesa y el $7 \%$ de los que prefirieron jugar. En cuanto al valor Vital el $11 \%$ de los niños y niñas prefirieron ir a jugar en la hora de su descanso y el $6 \%$ prefirieron sólo ver jugar a sus compañeros, pudimos observar que es más bajo el porcentaje de los niños y niñas que prefirieron descansar y no realizar alguna actividad.

Nos basamos en la Teoría subjetivista de Meinong que hace mención que el sujeto es el que le da valor a las cosas y pudimos comprobar que su teoría es correcta ya que al realizar la pregunta correspondiente conocimos que los niños le dan valor a las cosas, por ejemplo, la mayoría prefirió jugar con sus amigos en el recreo y la minoría prefirió ver jugar a los demás, una acción no tiene más valor que otra, sin embargo, de forma personal el niño y la niña tomó la decisión de qué hacer con sus preferencias y gustos personales.

Respecto al valor Moral todos los niños y niñas entrevistados escogieron la respuesta de devolver el juguete.

De acuerdo al valor Intelectual, el 11\% decidió 


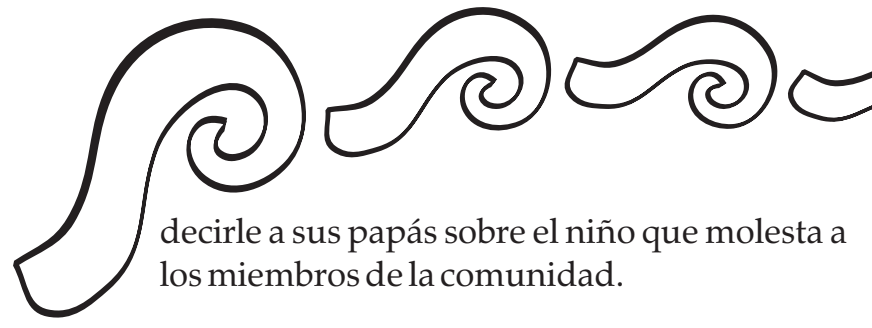

En cuanto al valor Religioso, las respuestas estuvieron muy empatadas ya que el 13\% eligió hacer oración en una situación donde tuviera miedo y el 11\% eligió prender la luz para sentirse más seguro.

En el valor Estético el 13\% de los niños y niñas entrevistadas prefirieron ser amigos de la niña fea pero amable a diferencia del $4 \%$ que eligió ser amigo de la niña bonita pero grosera.

Si tuvieran la oportunidad, la mayoría de los niños y niñas de la comunidad, ayudarían cuidando el ambiente.

Ixmalintla, Escuela Primaria: Cecilio Hernández

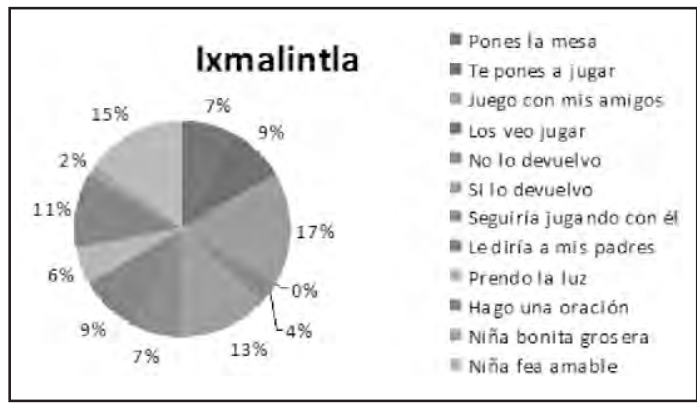

Ixmalintla fue la tercera comunidad que visitamos. En ella tuvimos la colaboración de 9 niños y niñas de $1^{\circ}$ y $2^{\circ}$ grado de primaria para realizar nuestra entrevista.

El valor Útil tuvo un $9 \%$ de quienes prefirieron salir a jugar en lugar de ayudar a su mamá a poner la mesa.

El segundo valor que manejamos es el valor Vital, $14 \%$ prefirió jugar y el $4 \%$ prefirió ver jugar a los demás. En cuanto al valor Moral la mayoría escogió la opción de "regresar el juguete" con un 13\%, este porcentaje dejó ver que en esta comunidad existe honestidad.

El siguiente valor que manejamos fue el valor
Intelectual, con este quisimos ver el sentido lógico que el niño plantea en alguna situación y pudimos comprobar que el $9 \%$ de los niños eligióla opción "B".

A los niños se les realizó una pregunta del valor Religioso y nos percatamos que el $11 \%$ prefirió prender la luz en lugar de hacer una oración para sentir mayor seguridad, lo anterior refleja que los niños no le dan importancia a su cultura religiosa.

En la Primaria Ixmalintla el valor Estético existe y se valora a través de las decisiones que los niños y niñas tomaron, ya que pudimos darnos cuenta que la superficialidad no es importante para ellos.

La mayoría de los niños, si tuvieran una oportunidad para ayudar a su comunidad, lo harían aprovechando y utilizando las cosas para no desperdiciar nada.

\section{Pemuxtitla, Escuela Primaria: Jaime Nunó}

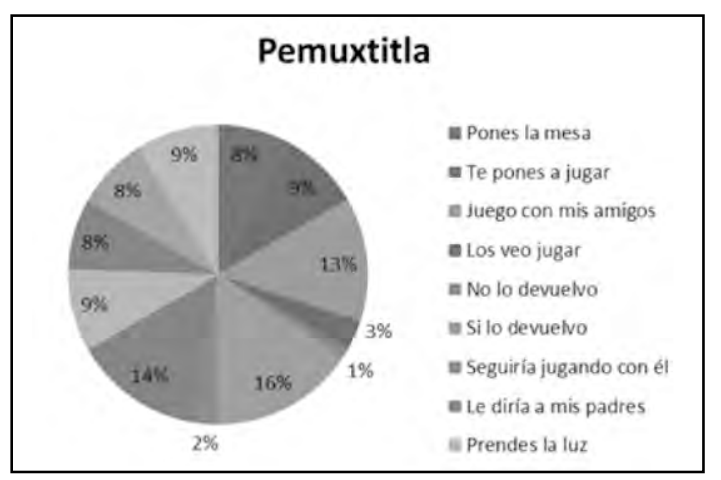

La última comunidad que visitamos fue Pemuxtitla, en esa comunidad se encuentra la primaria Jaime Nunó, entrevistamos a 15 niños y niñas en total de $1^{\circ}$ y $2^{\circ}$ grados.

Valor Útil: el 9\% de los niños y niñas eligieron salir a jugar, (respuesta "B") en cuanto a la respuesta " $\mathrm{A}$ " tuvo el $8 \%$, lo cual indica que la mayoría de los niños y niñas prefirieron ayudar a poner la mesa a su mamá. El Valor Vital: el 13\% prefirió hacer una actividad física 


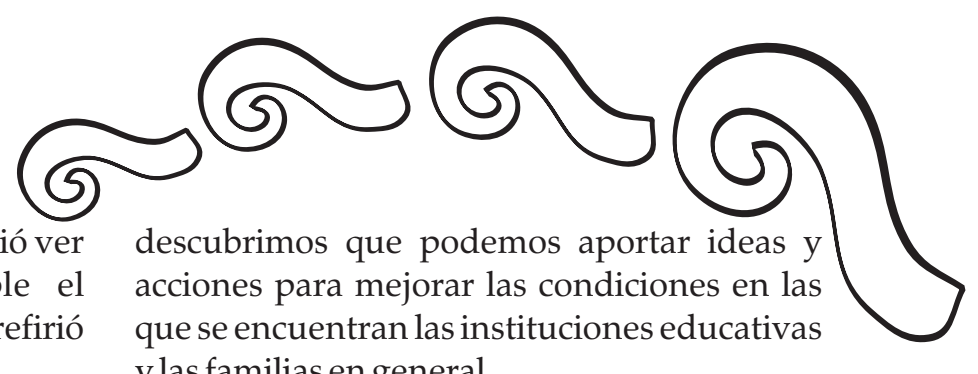

en la hora del recreo, mientras el 3\% eligió ver a sus compañeros jugar, es notable el resultado: la mayoría de los niños prefirió estar activos durante su descanso.

Valor Moral: la mayoría, con el 16\%, tomó la decisión de regresar el juguete que se había encontrado.

Valor Intelectual: el 14\% de los niños eligieron la respuesta " $\mathrm{B}$ " mientras solo el $2 \%$ eligió la respuesta " $\mathrm{A}$ ", con estos resultados nos dimos cuenta que son pocos los niños que prefirieron dejar las cosas como están.

Valor Religioso: el 9\% de los niños y niñas entrevistados escogieron la pregunta " $\mathrm{A}$ " prender la luz, mientras el $8 \%$ prefirió la pregunta "B" hacer una oración, lo que demuestra que casi la mitad de la muestra toma en cuenta su fe para resolver problemas. Valor Estético: los resultados fueron, el $8 \%$ escogió la respuesta " $\mathrm{A}$ ", y el $9 \%$ eligió la respuesta " $B$ ", pudimos darnos cuenta que un poco menos de la mitad de la muestra le da importancia a la belleza de las personas.

Max Scheler en La Ética Material de los Valores propone que los valores deben ser considerados por lo que son y no por el agrado o el deseo del sujeto. Lo anterior no coincide con los resultados que se obtuvieron en esta escuela, pues los niños prefirieron tomar en cuenta sus deseos y no la esencia de la persona.

La mayoría de los niños y niñas de la comunidad ayudarían llevando leña.

\section{Conclusiones}

Como investigadoras incursionamos en un ambiente natural para obtener experiencias de manera directa y así poder observar, entender y profundizar las conductas de los niños de las primarias de Molango.

Con base en las entrevistas que se aplicaron en las escuelas y en las visitas a las comunidades,

descubrimos que podemos aportar ideas y que se encuentran las instituciones educativas y las familias en general.

Los valores de los niños pequeños están definidos, en buena medida, por sus necesidades de subsistencia y por la búsqueda de aprobación de sus padres: sustento biológico y amor filial.

Se llevó a cabo la evaluación de la jerarquización de los valores: útil, vital, moral, intelectual, estético y religioso.

En la comunidad de Tenango predominó más el valor estético, como segundo valor se tuvo el moral con un porcentaje del $17 \%$ de alumnos que prefieren ser honestos con los juguetes perdidos que se encuentran.

Los siguientes valores: útil, intelectual y religioso tuvieron un porcentaje del $12 \%$ porque no todos practican oración en las escuelas ni rezan en su casa.

En la comunidad de Chalma el valor que predominó más fue el moral y se demostró que a todos les han inculcado la honestidad.

En la comunidad de Ixmalintla todos ponen en práctica el valor estético ya que no toman en cuenta lo superficial.

En la comunidad de Pemuxtitla el valor moral fue el que predominó porque todos mostraron honradez en las cosas ajenas.

Muchos de los niños y niñas quieren ayudar a su comunidad no contaminando con humo y basura y desean cortar leña para disminuir el trabajo de sus padres.

Esta investigación es interna (humanista) ya que los datos que se obtienen de esta se enfocan en las culturas, afectos, tradiciones e ideología de las personas de Molango y estos datos son profundos, subjetivos y enriquecedores. 

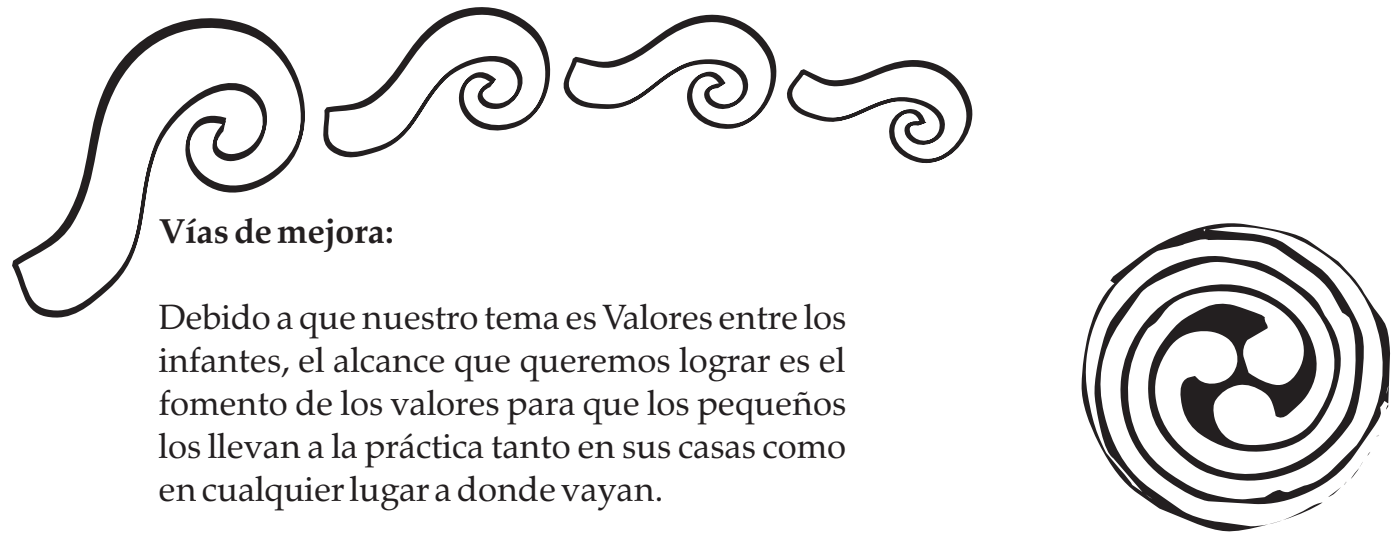

- Sería conveniente que los maestros propicien ambientes de concientización y apreciación de los valores.

- Implementar métodos de observación como checklist, bitácoras, diarios de aula, planeaciones, para que el docente esté consciente de las acciones favorables en torno a los valores.

- Escuela de valores para los padres de familia y para quienes los cuidan.

- Incrementar los valores en la escuela y en la casa, eligiendo un valor por mes y que toda la familia trabaje en éste.

- Impulsar a los niños a que no pierdan los valores, haciendo hincapié en las tradiciones y fiestas patrias o religiosas del calendario, donde los niños rescaten e integren los valores.
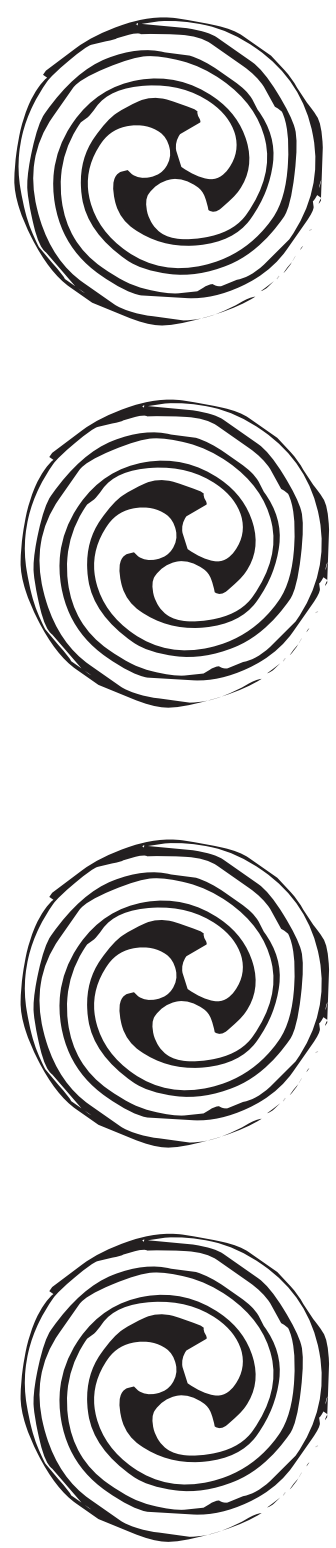


\section{Fuentes de consulta:}

SANZ, D., y Molina A. (1999). Violencia y abuso sexual en la familia. Editorial Lumen.

MARTÍNEZ, T. A. (1900-2001).Prevención de la violencia intrafamiliar. México D.F. Editorial Porrúa.

MADANES, C. (1993). Sexo, amor y violencia: estrategias de transformación. Editorial Paidós Ibérica, S. A.

MINUCHIN, S. Y Fishman H.C. (1988).Técnicas de Terapia Familiar. México. Paidós.

DIAZ, S. A. (1996). Educación y violencia familiar. Editorial DYKINSON, S.L.

MONROY, A. (1994). La dualidad del incesto: acto complementario. En Simposium (mayo 1994), De la perversión al amor maduro (55-60) Universidad Intercontinental.

GOICOECHEA, H. P.(n. d). Abuso sexual infantil: manual de formación para profesionales. Save the Children. Obtenida en noviembre de 2001, de http://www.savethechildren.es/ docs/Ficheros/91/Manual.pdf.

FAURA, S. J. F. (n.d). Promoción del buen trato y prevención del maltrato en la infancia en el ámbito de la atención primaria de la salud. Obtenida el 15 de Abril de 2005, en http://www.aepap.org/previnfad/Maltrato.htm.
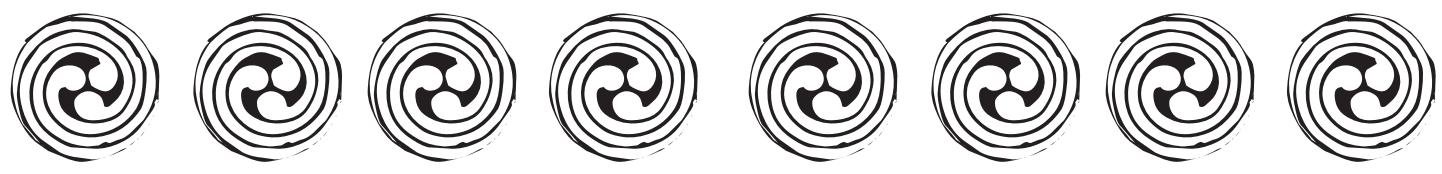


\section{Anexo 1. Fotografías}

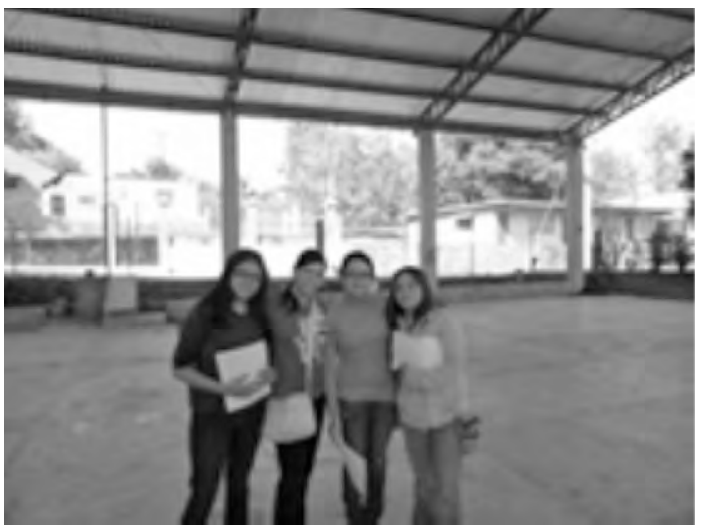

En la escuela primaria José Ma. Morelos y Pavón, en la comunidad de Tenango.

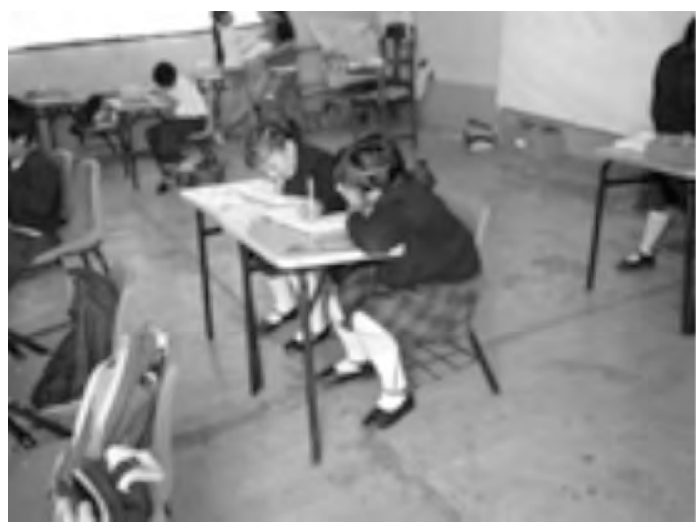

Alumnos $1^{\circ}$ y $2^{\circ}$ en clase de matemáticas, Chalma.

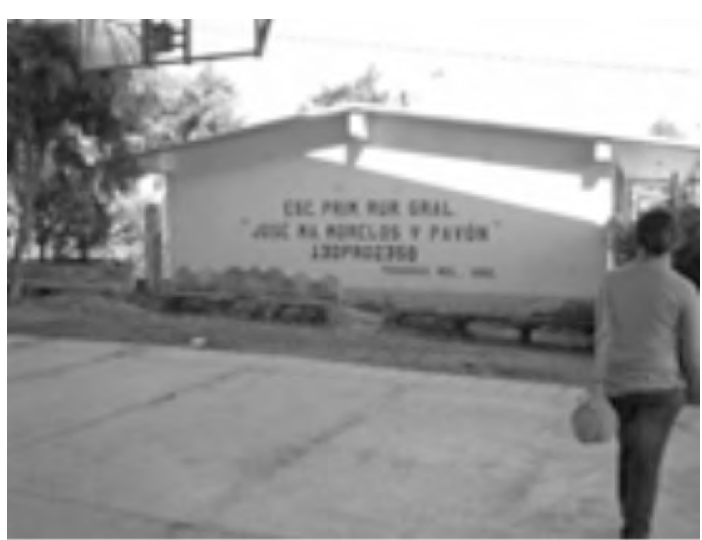

Llegando a la escuela primaria, en Tenango.

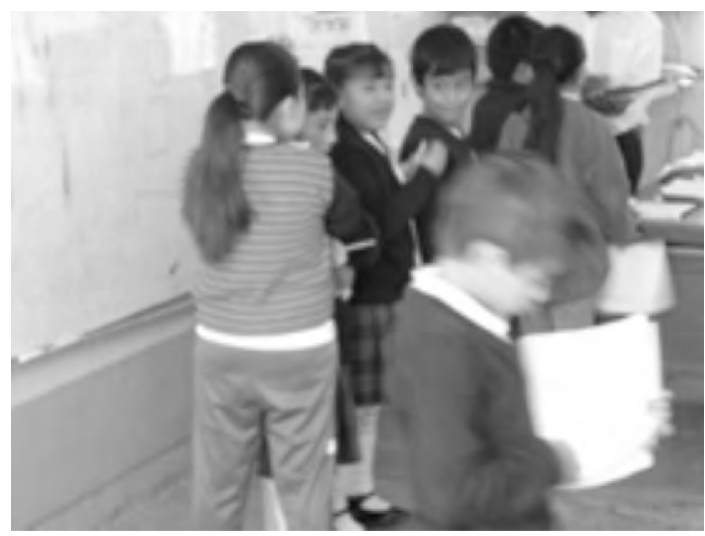

Revisión de ejercicios.

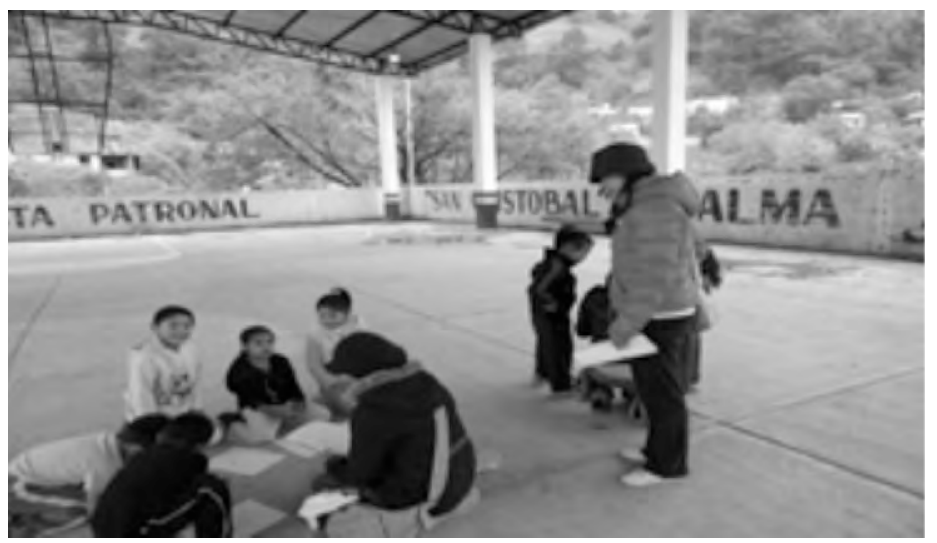

(9) 27 @

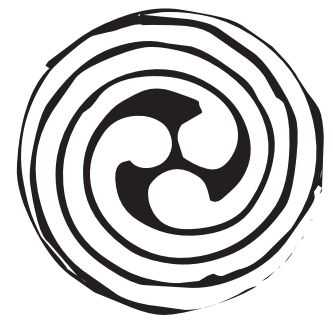

Entrevistando a los niños de la comunidad de Chalma, escuela primaria Netzahualcóyotl. 


$$
\rho^{\infty}
$$

